\title{
EFFECT OF CYCLONE INLET VELOCITY AND VORTEX FINDER HEIGHT ON COARSE WHEAT BRAN DUST SEPARATION
}

\begin{abstract}
Abdel-Hadi, M. A.*
ABSTRACT

Experimental study was performed for evaluating a vast number of equations derived from reviews to determine the performance of cyclone for overall collection efficiency, cut size diameter and pressure drop of cyclone. These equations were used based on the geometrical design of cyclones for operation at the ambient temperatures under different vortex finder heights $(0.0,0.05,0.10,0.15$ and $0.20 \mathrm{~m})$ and inlet velocities $(9.3$, $11.5,18.5,25.4$ and $28.3 \mathrm{~m} / \mathrm{s})$. The cut size diameter of coarse wheat bran as inlet dust was estimated using direct empirical method and by Stock's number based on Euler's number. Both methods were also used to predict the overall collection efficiency. Experimental data were compared with the predictions of Lapple's theory and Iozia \& Leith's logistic method. The results showed that only the pressures drop based on Cocker model in the range of 9.3 to $18.5 \mathrm{~m} / \mathrm{s}$ inlet velocity proved accurate predictions. The operation at inlet velocity of $18.5 \mathrm{~m} / \mathrm{s}$ was the best operational condition due to high collection efficiency of 96.4, 98.9, 98.5, 98.3 and 98.7\%; and low pressure drop of 1173, 1324, 1249, 1137 and $1419 \mathrm{~Pa}$ at vortex finder height of $0.0,0.05,0.10,0.15$ and $0.20 \mathrm{~m}$ respectively, across the cyclone.
\end{abstract}

Keywords: Cyclone; collection efficiency; pressure drop; inlet velocity

\footnotetext{
*Associate Prof. of Agric. Eng. Dep., Fac. of Agric., Suez Canal Univ., 41522 Ismailia, Egypt.
} 


\section{NOMENCLATURE}

A

B

$\mathrm{C}_{\text {in }}$

$\mathrm{C}_{\text {out }}$

D

$\mathrm{d}_{50}$

$\mathrm{d}_{\mathrm{c}}$

$\mathrm{D}_{\mathrm{e}}$

$\mathrm{Di}_{\mathrm{i}}$

Dih

$d_{p}$

$\mathrm{d}_{\mathrm{pi}}$

$\mathrm{Eu}$

g

$\mathrm{H}$

$\mathrm{h}_{1}$

$\mathrm{h}_{2}$

$\mathrm{h}_{3}$

$\mathrm{L}$

$\mathrm{L}_{1}$

$\mathrm{L}_{2}$

$\mathrm{L}_{\mathrm{e}}$

$\mathrm{L}_{\mathrm{i}}$

$l_{\mathrm{n}}$

$\mathrm{m}_{\mathrm{i}}$

$\mathrm{N}$

$\mathrm{N}_{\mathrm{e}}$

$\mathrm{P}$

$\mathrm{Pa}$

Ptube

Q

$\mathrm{Re}_{\mathrm{ann}}$

$\mathrm{Re}_{\mathrm{c}}$

$\mathrm{Re}_{\text {in }}$

$\mathrm{Re}_{\mathrm{o}}$

$\mathrm{S}$

Stk $k_{50}$

$\mathrm{V}_{\mathrm{c}}$

$\mathrm{V}_{\mathrm{i}}$

$\mathrm{V}_{\mathrm{o}}$

$\mathrm{V}_{\mathrm{t} \text { max }}$

$\mathrm{Wg}_{\mathrm{g}}$

$\mathrm{W}_{\mathrm{w}}$

$\mathrm{Z}_{\mathrm{c}}$

$\beta$

$\Delta \mathrm{P}$

$\eta_{\mathrm{i}}$

$\eta_{\mathrm{o}}$

$\mu \mathrm{g}$

$\xi_{\mathrm{c}}$

$\rho g$

$\rho_{p}$

$\rho_{\mathrm{w}}$

inlet cross sectional area of cyclone flow, $\mathrm{m}^{2}$

diameter of the dust exit, $m$

weight of inlet dust, gram

weight of outlet dust, gram

cyclone body diameter, $\mathrm{m}$

cut size diameter of particle which is collected with $50 \%$ efficiency, $\mu \mathrm{m}$

the core diameter, $\mathrm{m}$

cyclone air outlet or vortex finder diameter, $\mathrm{m}$

cyclone inlet diameter, $\mathrm{m}$

inlet hydrodynamic diameter, $\mathrm{m}$

particle diameter, $\mathrm{m}$ or $\mu \mathrm{m}$

average particle diameter of the $i$ th fraction, $\mathrm{m}$

Euler's number, dimensionless

gravity acceleration $9.81\left(\mathrm{~m} / \mathrm{sec}^{2}\right)$

total height of the cyclone, $\mathrm{m}$

height of the cylindrical part of cyclone, $\mathrm{m}$

height of the conical part of cyclone, $\mathrm{m}$

height of the dust tube, $\mathrm{m}$

pressure head

height of the water of manometer tube, $m$

height of the air of manometer tube, $m$

distance between the outlet section and the cylindrical barrel top, $\mathrm{m}$

distance between the inlet section and the cyclone center, $\mathrm{m}$

natural vortex length (inner vortex), $m$

mass fraction of particles in the $i$ th size range, $\%$

number of cyclones in the system, in parallel

effective number of turns made in the cyclone

pressure, Pascal

Pascal

perimeter inlet tube, $\mathrm{m}$

air flow rate, $\mathrm{m}^{3} / \mathrm{h}$ or $\mathrm{m}^{3} / \mathrm{s}$

annular Reynold's number, dimensionless.

Reynold's number based on cyclone diameter, dimensionless.

Reynold's number based on inlet diameter, dimensionless.

Reynold's number based on the outlet diameter, dimensionless.

vortex finder height, $\mathrm{m}$

Stock's number of a particle having a 50\% probability of separation, dimensionless

axial air velocity in cylindrical part, $\mathrm{m} / \mathrm{s}$

inlet or tangential velocity, $\mathrm{m} / \mathrm{s}$

outlet velocity, $\mathrm{m} / \mathrm{s}$

the maximum air tangential velocity, $\mathrm{m} / \mathrm{s}$

specific gravity of air

specific gravity of water

core length, $\mathrm{m}$

slope parameter

cyclone pressure drop, Pascal

collection efficiency for any particle size, $\%$

overall dust collection efficiency, \%

air viscosity, $1.8 \times 10^{-5} \mathrm{~kg} / \mathrm{m}$-sec

pressure drop coefficient, "head loss"

air density, $1.18 \mathrm{~kg} / \mathrm{m}^{3}$

particle density, $\mathrm{kg} / \mathrm{m}^{3}$

water density, $\mathrm{kg} / \mathrm{m}^{3}$ 


\section{INTRODUCTION}

I $\mathrm{n}$ industrial processes, cyclones are one of the most useful equipment for separating dispersed particles from their carrying material. The material mixture flow enters the cyclone and centrifugal forces due to its swirl motion cause the particles to gain a relative velocity in radial direction leading to the separation of particles from the main flow. However, cyclones also possess a relatively large effective collection region and relatively low-pressure drop. In comparison with equipment used for this process, cyclones are preferred for their simple design, inexpensiveness to manufacture, low maintenance costs, and adaptability to a wide range of operating conditions. In addition, they allow continuous material removal with less clogging than the fabricated filters. Against their apparent simplicity, flow and collocation characteristics of cyclones are complicated and the performance of a cyclone is highly sensitive to any change in geometrical design and operating conditions (Qian et al., 2006). The main performance characteristics of cyclone separators are collection efficiency, fractional efficiencies and pressure drop. Various aspects of the cyclone have been thoroughly studied by many researchers with the objective of improving or more efficiently control its performance. Some of the work has been related to the influence of cyclone design and operating parameters, some to mathematical modeling and simulation, and others to design modifications (Yalcin et al., 2003; Jiao et al., 2006 \& Azadi et al., 2010). The main objective of this study was to examine the effect of cyclone vortex height and inlet velocity on the flow field behavior and performance parameters via cut-diameter $\left(\mathrm{d}_{50}\right)$, collection efficiency and pressure drop. Furthermore, to assess the predictive validity of some literature correlations in comparison with the measured data to put the data into better use with the existing theories.

\section{CYCLONE EQUATIONS ANALYSES}

The particles' collection inside a cyclone is a result of the main forces acting on them, which drive the solids to the cyclone walls: centrifugal, drag and gravitational. In addition, there are other forces, not entirely understood and often neglected, such as particle-particle and particle-wall 
friction, which can influence the collection process (Gil et al., 2001). Moreover, the collection efficiency depends on the particle size and is eventually referred to as "grade" efficiency. It increases from zero for very tiny particles to $100 \%$ for coarse particles. The particle size recovered up to $50 \%$ is called the cut-size or $\mathrm{d}_{50}$. Traditional cyclone literature has given direct empirical correlations for $d_{50}$ based on the cyclone geometry and flow properties as listed in Table 1.

Table 1: Traditional cyclone literature for $\mathrm{d}_{50}$.

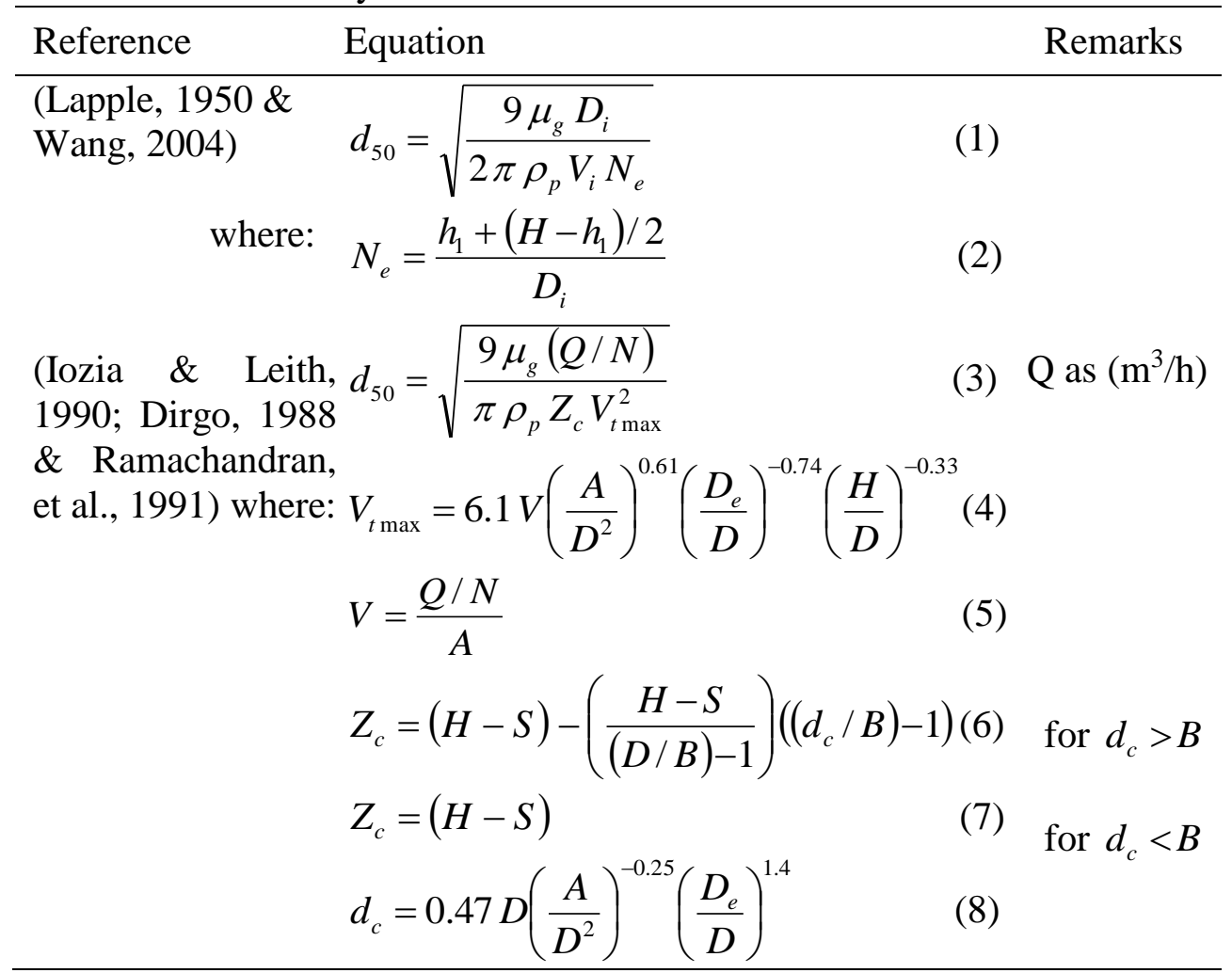

More modern cyclone design methods characterize the separation efficiency of geometrically similar cyclones by the Stock's number (Stk50) (Dewil et al., 2008) equation (9), because it contains the main operating variables of the flow, $\mathrm{d}_{50}$ and the air velocity in the cyclone body $\left(\mathrm{V}_{\mathrm{c}}\right.$ ) equation (10) (Overcamp \& Scarlett, 1993).

$$
S t k_{50}=\frac{\rho_{p} d_{50}{ }^{2} V_{c}}{18 \mu_{g} D}
$$


PROCESS ENGINEERING

$$
\text { where: } \quad V_{c}=\frac{Q}{\pi D^{2} / 4}
$$

Also, Svarovsky (1981 \& 1986) found the relationship between dimensionless Eu and $\mathrm{Stk}_{50}$ as in equation (11).

$$
\begin{aligned}
& S t k_{50}=\frac{12}{(E u)^{2}} \\
& \text { where: } \quad E u=\xi_{c} \frac{\pi^{2} D^{4}}{16 A^{2}}
\end{aligned}
$$

Euler's number influences by the pressure drop coefficient $\left(\xi_{\mathrm{c}}\right)$ in cyclone. Many empirical models in the literature give the $\left(\xi_{\mathrm{c}}\right)$. Four empirical models have been chosen as shown in Table 2 .

Table 2: The empirical models in the literature used for calculating the pressure drop coefficient, $\xi_{\mathrm{c}}$ "head loss".

\begin{tabular}{lll}
\hline Reference & Equation & Remarks \\
\hline $\begin{array}{l}\text { (Shepherd \& } \\
\text { Lapple, 1939) }\end{array}$ & $\xi_{c}=\left(\frac{16 A}{D_{e}^{2}}\right)$ & $\begin{array}{l}\text { Tangential } \\
\text { inlet; ambient } \\
\text { air conditions }\end{array}$ \\
$\begin{array}{l}\text { Casal \& } \\
\text { Martinez, }\end{array}$ & $\xi_{c}=11.3\left(\frac{A}{D_{e}^{2}}\right)^{2}+3.33$ & \\
1983) & $\xi_{c}=20\left(\frac{A}{D_{e}^{2}}\right)\left(\frac{S / D}{(H / D)\left(h_{1} / D\right)(B / D)}\right)^{\frac{1}{3}}(15)$ & \\
$($ Dirgo, 1988) & (14) & $\begin{array}{l}\text { Comparative } \\
\text { study of six } \\
\text { correlations }\end{array}$ \\
\hline
\end{tabular}

From equation $\left(9,11\right.$ and 12) another value of $\mathrm{d}_{50}$ could be derived as follows:

$$
d_{50}=\sqrt{\frac{S t k_{50} 18 \mu_{g} D}{\rho_{p} V_{c}}}
$$

For the prediction of the collection efficiency of any particle size $\left(\eta_{i}\right)$ which is also known as a fractional efficiency curve, it can be expressed as a function of particle diameter $\left(\mathrm{d}_{\mathrm{pi}}\right)$ according to Wang (2004) equation (18). 


$$
\eta_{i}=1 /\left[1+\left(\frac{d_{50}}{d_{p i}}\right)^{2}\right]
$$

Moreover, Iozia and Leith (1990) determine the slope parameter ( $\beta$ ) as fallow:

$$
\ln (\beta)=0.62-0.87 \ln \left(d_{50}(\mathrm{~cm})\right)+5.21 \ln \left(\frac{A}{D^{2}}\right)+1.05\left(\ln \left(\frac{A}{D^{2}}\right)\right)^{2}
$$

So that the collection efficiency can be calculated through the logistic equation together with the $\mathrm{d}_{50}$, value predicted by the method mentioned earlier is obtained by equation (20) according to Iozia \& Leith (1990) and Ramachandran et al. (1991).

$$
\eta_{i}=1 /\left[1+\left(\frac{d_{50}}{d_{p i}}\right)^{\beta}\right]
$$

Cyclone pressure drop is one of the major performance parameters playing a significant role in cyclone design and control. The cyclone static pressure drop $(\Delta \mathrm{P})$ is usually calculated as the pressure difference between the inlet and the average pressure across the vortex finder exit (Hoekstra, 2000). The pressure drop is proportional to cyclone design assuming the square inlet velocity $\left(\mathrm{v}_{\mathrm{i}}\right)$ and pressure drop coefficient $\left(\xi_{\mathrm{c}}\right)$ "head losses". According to Shepherd \& Lapple (1939) the cyclone pressure drop is calculated as:

$$
\Delta P=\xi_{c} \frac{\rho_{g} V_{i}^{2}}{2}
$$

In Table 2 the $\xi \mathrm{c}$ empirical model Shepherd \& Lapple and Coker was obtained by assuming static pressure, model Casal \& Martinez obtained from derived the statistical analysis on an experimental date and model Dirgo as a function of cyclone dimension equation. Moreover, the pressure drop equation (22) is related to the square air velocity in the cyclone body $\left(V_{\mathrm{c}}\right)$ equation (10), i.e. based on the cyclone diameter and a friction resistance referred to as the dimensionless Eu (Svarovsky, 1981, 1986). The pressure drop is hence written as:

$$
\Delta P=E u \frac{\rho_{g} V_{c}^{2}}{2}
$$

Zhu and Lee (1999) investigated the effects of the vortex finder length (inner vortex) on the particle collection efficiency using seven different 
cyclones, and suggested that the difference between the cyclone cylinder height and vortex finder length played a significant role in the particle collection characteristics, and that the vortex finder length could be optimized. The experience with industrial units has shown that, the vortex finder length has a relevant influence in the collection efficiency process; little experimental work has been done since the empirical approach of Alexander (1949) was found as:

$$
\frac{l_{n}}{D}=2.3 \frac{D_{e}}{D}\left(\frac{D^{2}}{A}\right)^{1 / 3}
$$

However, Bryant et al. (1983) found experimentally that Alexander (1949) formula for the natural vortex length in many cases cannot predict the length of the vortex. Therefore, they proposed the following formula.

$$
\frac{l_{n}}{D}=2.26\left(\frac{D_{e}}{D}\right)^{-1}\left(\frac{D^{2}}{A}\right)^{-0.5}
$$

The modern geometric design according to $\mathrm{Ji}$ et al. (1991) investigated the following correlation:

$$
\frac{l_{n}}{D}=2.4\left(\frac{D_{e}}{D}\right)^{-2.25}\left(\frac{D^{2}}{A}\right)^{-0.361}
$$

Moreover, Büttner (1999) found two distinct types of cyclone operation. First type, when the operation with $l_{n} \geq \mathrm{H}$ the natural vortex length is equal or longer than the physical height of cyclone; the vortex end reaches the bottom of the cyclone. This is the most advisable mode of operation, since it leads to high collection efficiency. It corresponds to cyclones with relatively high inlet Reynold's numbers (approximately ranging from $2 \times 10^{3}$ to $2 \times 10^{4}$ ) and H/D ratios within 2-10. Second type when the operation with $l_{\mathrm{n}}<\mathrm{H}$ the collection performance is poor, because the vortex end attaches to the cyclone wall, disturbing the solids strands that are already separated and decreasing the efficiency through instability and re-entrainment. This mode of operation corresponds to a low inlet Reynold's numbers $\left(<10^{3}\right)$ or very tall cyclones $(\mathrm{H} / \mathrm{D}>15)$. Hoffmann et al. (1995 \& 2001) found that, the height of the vortex finder, $S$, does not influence the position of the end of natural vortex length. On the contrary, the vortex finder diameter (outlet diameter, $\mathrm{D}_{\mathrm{e}}$ ) 
has been identified as a definite influence. The trend most frequently observed is an increased natural length with an increased $D_{e}$ (Hoffmann et al., 2001). Owing to the difference in the size, geometry of the cyclone and the operation condition, the ranges of the Reynold's number for the cyclone in different laboratory studies are quite different (Kuo \& Tsai, 2001). Table 3 shows different Reynold's number of the cyclone.

Table 3: Reynold's number of the cyclone in different laboratory studies.

\begin{tabular}{lll} 
Reference Equation Remarks \\
\hline
\end{tabular}

(Stairmand, 1951 \& Chan, 1984)

$$
\begin{aligned}
& \operatorname{Re}_{i n}=\frac{\rho_{g} V_{i} D_{i h}}{\mu_{g}} \\
& D_{i h}=\frac{4 A}{P_{\text {tube }}}
\end{aligned}
$$

(Beeckmans \& Kim, 1977) $\operatorname{Re}_{c}=\frac{\rho_{g} V_{i} D}{\mu_{g}}$

(Saltzman \& Hochstrasser,

$$
\operatorname{Re}_{o}=\frac{\rho_{g} V_{o} D_{e}}{\mu_{g}}
$$

Based on

hydrodynamic

inlet diameter

(Moore \& McFarland,

$$
\mathrm{Re}_{a n n}=\frac{\rho_{g} V_{i}\left(D-D_{e}\right)}{2 \mu_{g}} \text { (30) } \begin{aligned}
& \text { based on } \\
& \text { cyclone and } \\
& \text { outlet diameter }
\end{aligned}
$$

\section{MATERIALS AND METHODS}

\section{Experimental setup}

A cyclone was constructed at the Agricultural Engineering Department, Faculty of Agriculture, Suez-Canal University as shown in Fig. 1. It was fabricated from galvanized steel sheet of $1.5 \mathrm{~mm}$ thick. The dimension and specification of the experimental unit are tabulated in Table 4. The air supply unit consists of an electric blower 0-16000 rpm model OK-405 APT. It was connected to the air inlet pipe and set of input dust particle, as well as a manometer for pressure measurements made from the glass diameter of $2.56 \mathrm{~mm}$ Plate 1 . The inlet and outlet velocities $(\mathrm{m} / \mathrm{s})$ were measured by anemometer fan type model MT-4005 Prokit's Industries Co., New Taipei City, Taiwan. 


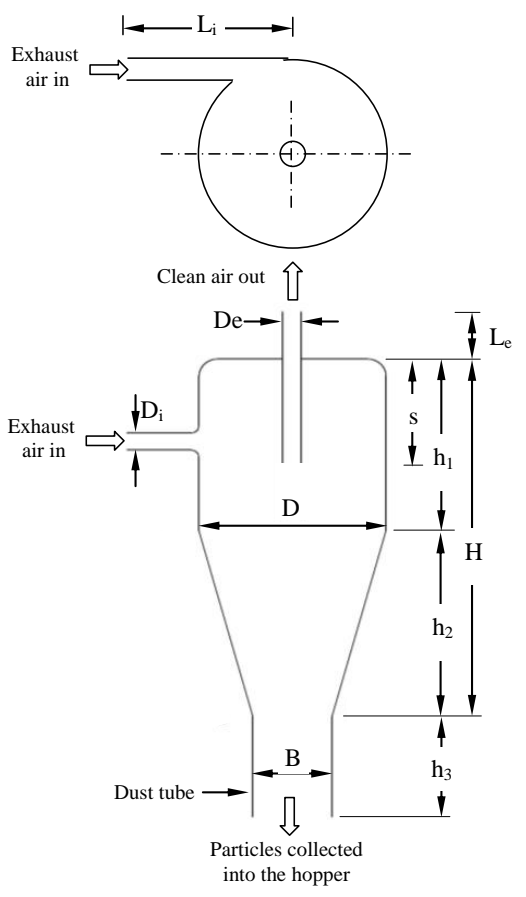

(a)

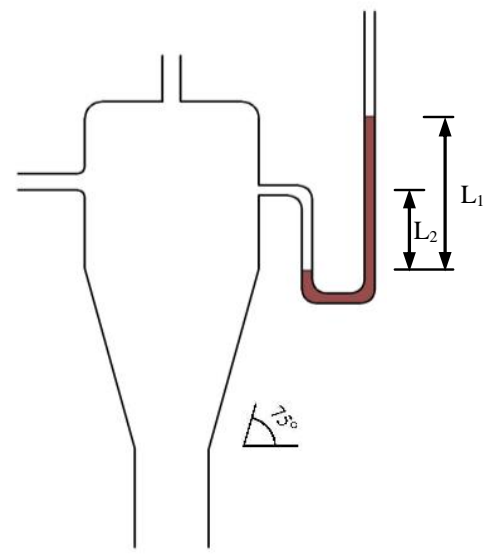

(b)

Fig. 1. (a) Sketch of cyclone detail and (b) manometer attached to the cyclone.
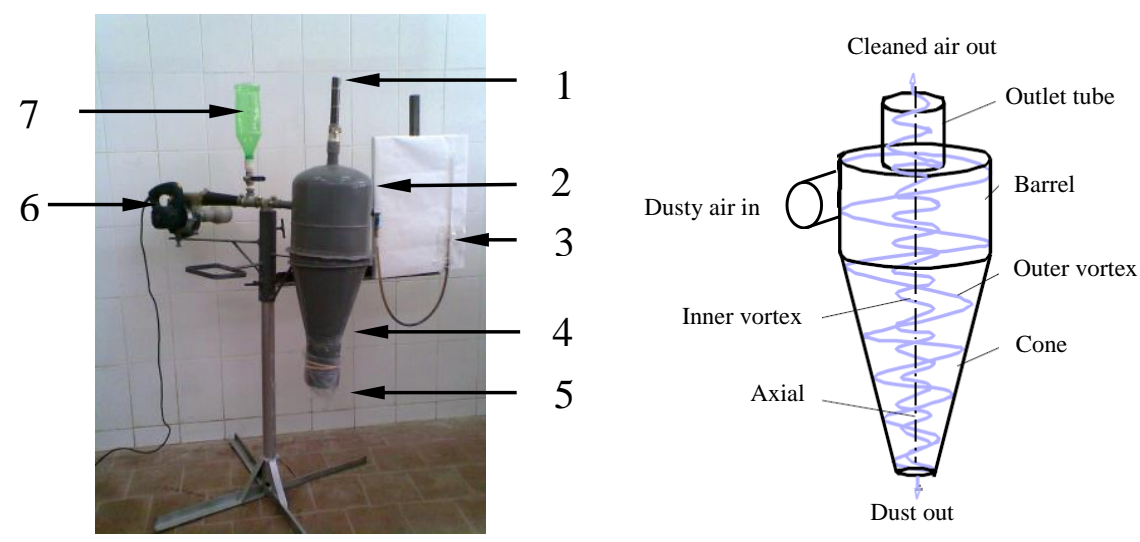

1- Distance between the outlet section and the cylindrical barrel top

2- Cylindrical part of cyclone

4- Conical part of cyclone 6- Air supply unit
3-Watermanometer

5- Dust bin

7- Set of input dust

Plate 1. Cyclone annexed to the water manometer and general flow pattern of a cyclone. 
PROCESS ENGINEERING

Table 4: Dimension and specification of the experimental setup.

\section{Dimensions}

\section{Designed values}

Cyclone body diameter, D (m)

0.25

Cyclone inlet diameter, $\mathrm{D}_{\mathrm{i}}(\mathrm{m})$

0.025

Dust exit diameter, B (m)

0.105

Flow rate based on inlet air velocity, $\left(\mathrm{m}^{3} / \mathrm{h}\right) \quad 16.4,20.3,32.7,44.9$ and 50.0

Height of the conical part of the cyclone, $\mathrm{h}_{2}(\mathrm{~m}) 0.275$

Height of the cylindrical part of cyclone, $h_{1}(m) \quad 0.255$

Height of the dust tube, $\mathrm{h}_{3}(\mathrm{~m})$

0.15

Inlet air velocity $(\mathrm{m} / \mathrm{s})$

$9.3,11.5,18.5,25.4$ and 28.3

Outlet diameter, $\mathrm{D}_{\mathrm{e}}(\mathrm{m})$ 0.025

Outlet air velocity $(\mathrm{m} / \mathrm{s})$

5.1, 6.2,9.6, 12.4 and 14.2

Ambient temperature $(\mathrm{K})$ 293

Total height of the cyclone, $\mathrm{H}(\mathrm{m})$

0.53

Vortex finder height, S (m)

$0.0,0.05,0.10,0.15$ and 0.20

\section{Geometric design}

One of the most popular design guidelines which suggested by Stairmand (Kuo \& Tsai, 2001) is the cylinder height and the exit tube length should be 1.5 and 0.5 times the cyclone body diameter, respectively for the design of a high-efficiency cyclone (Safikhani et al., 2010). A comparison between Stairmand design and the fabricated experimental unit is shown in Table 5.

Table 5: Comparison between Stairmand design and the fabricated experimental unit.

\begin{tabular}{|c|c|c|c|c|c|c|c|c|}
\hline Cyclone & $\mathrm{D}_{\mathrm{i}} / \mathrm{D}$ & $\mathrm{D}_{\mathrm{e}} / \mathrm{D}$ & $\mathrm{H} / \mathrm{D}$ & $\mathrm{h}_{1} / \mathrm{D}$ & $\mathrm{S} / \mathrm{D}$ & $\mathrm{B} / \mathrm{D}$ & $\mathrm{L}_{\mathrm{i}} / \mathrm{D}$ & $\mathrm{Le}_{\mathrm{e}} / \mathrm{D}$ \\
\hline Stairmand design & 0.5 & 0.5 & 4.0 & 1.5 & 0.5 & 0.36 & 1.0 & 0.618 \\
\hline \multicolumn{9}{|c|}{ Vortex height of Exp. unit, $S(m)$} \\
\hline 0.00 & 0.1 & 0.1 & 2.12 & 1.02 & 0.0 & 0.42 & 0.884 & 0.8 \\
\hline 0.05 & 0.1 & 0.1 & 2.12 & 1.02 & 0.2 & 0.42 & 0.884 & 0.6 \\
\hline 0.10 & 0.1 & 0.1 & 2.12 & 1.02 & 0.4 & 0.42 & 0.884 & 0.4 \\
\hline 0.15 & 0.1 & 0.1 & 2.12 & 1.02 & 0.6 & 0.42 & 0.884 & 0.2 \\
\hline 0.20 & 0.1 & 0.1 & 2.12 & 1.02 & 0.8 & 0.42 & 0.884 & - 0.0 \\
\hline
\end{tabular}




\section{Collection efficiency}

If a size distribution of the inlet particles is known, the overall collection efficiency of a cyclone can be calculated based on the cyclone fractional efficiency $\left(\eta_{\mathrm{i}}\right)$. The overall collection efficiency $\left(\eta_{\mathrm{o}}\right)$ of a cyclone is the weighted average of the collection efficiencies for the various size ranges as given by the following equation:

$$
\eta_{o}=\Sigma \eta_{i} m_{i}
$$

For laboratory tests, representative samples of 50 grams were taken from coarse wheat bran as inlet dust. Size analysis of the samples showed a particle size of $96.7 \%$ passing $250 \mu \mathrm{m}$ sieve size and defined as powders according to (Lees, 2005). The full-size distribution in particle diameter $(\mu \mathrm{m})$ obtained by a combination of sieving is given in Fig. 2 . The particle density and specific gravity of the material were determined as 271.7 $\mathrm{kg} / \mathrm{m}^{3}$ and 0.272 , respectively.

The inlet and outlet dust were determined using the electric balance model BS30-Series. The outlet dust was collected at the end of each test run inside the dust bin, and it was used to estimate the overall dust collection efficiency. The overall dust collection efficiency $\left(\eta_{\mathrm{o}}\right)$ is the weight ratio of the dust collected to the dust entering the cyclone.

$$
\eta_{o}=\left(1-\left(\frac{C_{\text {out }}}{C_{\text {in }}}\right)\right) * 100
$$

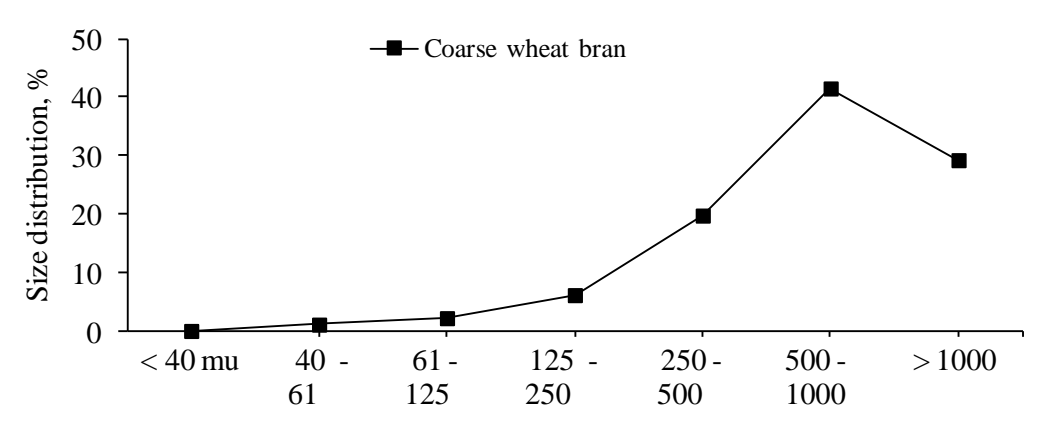

Fig. 2. The full size per $\mu \mathrm{m}$ distribution obtained by a combination of different sieves. 


\section{Cyclone pressure drop}

In this study, pressure drops $(\Delta \mathrm{P})$ per Pascal $(\mathrm{Pa})$ were measured on the cyclone by water manometer Plate 1 and estimated by following equations (Frank, $2003 \&$ Bruce et al., 2006).

$$
\begin{array}{r}
w_{g} L+w_{g} L_{2}=w_{w} L_{1} \\
L=\frac{w_{w} L_{1}-w_{g} L_{2}}{w_{g}} \\
P=\left(\frac{w_{w} L_{1}-w_{g} L_{2}}{w_{g}}\right) w_{g} * g * 1000
\end{array}
$$

\section{RESULTS AND DISCUSSION}

\section{Collection efficiency}

Fig. 3 presents the collection efficiency of the experimentally measured values with those of the conventional cyclone's Lapple model (Lapple, 1950) and Iozia \& Leith (1990) at different inlet velocities.

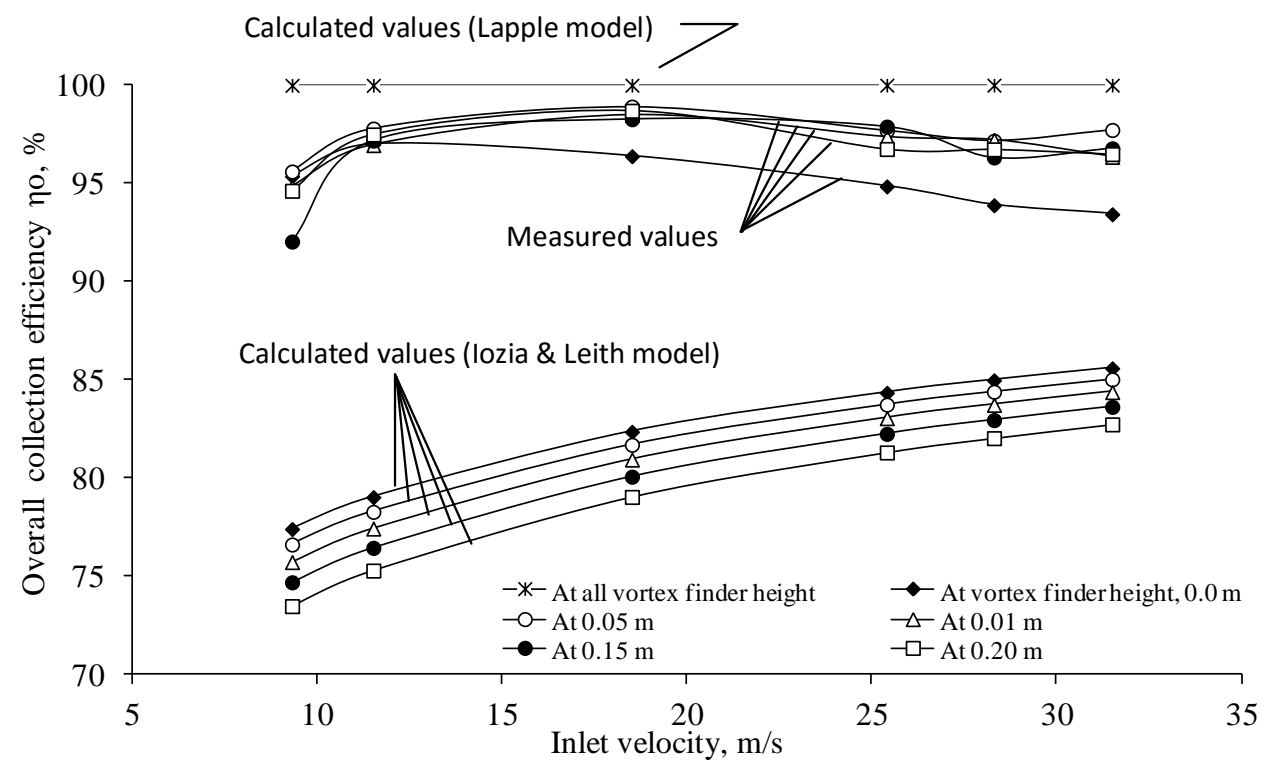

Fig. 3. Comparison between the calculated and measured values of overall collection efficiency at different inlet velocities. 
The collection efficiencies of all cyclones are seen to increase with the increase of the inlet velocity. But a very high inlet velocity would decrease the collection efficiency because of increased turbulence and saltation/re-entrainment of particles (Chuah et al., 2003). In the model Iozia \& Leith, the collection efficiency increased by about 76.1, 77.8, $81.3,83.4$ and $84.7 \%$ at $9.3,11.5,18.5,25.4$ and $28.3 \mathrm{~m} / \mathrm{s}$, respectively; with vortex finder height $0.0 \mathrm{~m}$, while the collection efficiency decreased with the increase of vortex finder height at the same inlet velocity. These results are in agreement with the data published by Lim et al. (2004). The Lapple model, not include the term vortex finder height and the collection efficiency arrived at $99.9 \%$ at all inlet velocity. The maximum collection efficiency of the experimentally measured and the calculated values after the application of Lapple models were 98.9 and 99.9\%, respectively at vortex finder height $0.05 \mathrm{~m}$ and $18.5 \mathrm{~m} / \mathrm{s}$ inlet velocity. The result is in good agreement with those obtained from Chuah et al. (2003), which found that the optimum operating velocity is around 18 $\mathrm{m} / \mathrm{s}$. The minimum collection efficiency of the experimentally measured and the calculated values after application of Lapple models were 94.0 and $99.98 \%$, respectively at vortex finder height $0.15 \mathrm{~m}$ and $9.3 \mathrm{~m} / \mathrm{s}$ inlet velocity. The minimum difference between the measured and the calculated value was $1.1 \%$, while the maximum was $6.0 \%$. In order to put the data into better use the experimental data obtained in this study were compared with the existing theories. The Lapple model is easy to use and acceptable to define the collection efficiency. The corresponding of height collection efficiency maybe influenced by operation with natural vortex length $\left(l_{n}\right)$. The comparative of results with Büttner (1999) showed that, the natural vortex lengths were $0.29,0.5$ and $18.5 \mathrm{~m}$ according to (Alexander, 1949; Bryant et al., 1983 \& Ji et al., 1991), respectively. Meanwhile, the value according to Ji et al. (1991) was longer than a total height of cyclone $\mathrm{H} 0.53 \mathrm{~m}$, and H/D ratios equal 2.12 within 2-10 and higher Reynold's numbers based on hydrodynamic inlet diameter and inlet velocity from 15242 to 46381 . This means that, the collection efficiency is dependent on other dimensions of the cyclone, Reynold's number, Stokes number and the ratio of the air density to the particle density (Pant et al., 2002). 
The modern cyclone design methods characterize the separation efficiency of geometrically similar cyclones by the Stk 50 . The calculated values of $\mathrm{d}_{50}$ using the direct empirical methods Iozia \& Leith, Lapple and based the above mentions four models pressure drop coefficient, Stk $_{50}$ are presented in Table 6. Both direct empirical methods and Stk s0 $_{5}$ methods based on $\xi_{\mathrm{c}}$ show that with the increase of inlet velocity, the cut size diameter of the particles to be separated is decreased. As the inlet velocity increases, the finer particle will be subjected to increasing centrifugal force, leading to a greater degree of separation (Bose et al., 2010). Except of predictions by Lapple model, none of the equations showed accurate predictions of cut size diameter.

Table 6: Cut size diameter $\mathrm{d}_{50} \mu \mathrm{m}$ based on direct empirical and Stokes number methods at vortex finder height of $0.0 \mathrm{~m}$.

\begin{tabular}{|c|c|c|c|c|c|c|}
\hline \multirow{3}{*}{$\begin{array}{c}\text { Inlet } \\
\text { Velocity, } \\
\mathrm{m} / \mathrm{s}\end{array}$} & \multicolumn{6}{|c|}{ Cut size, $\mu \mathrm{m}$} \\
\hline & \multicolumn{4}{|c|}{ Direct empirical methods } & \multicolumn{2}{|c|}{ Based on Stk 50} \\
\hline & Iozia \& Leith & $\overline{\text { Lapple }}$ & Digro & Coker & $\begin{array}{c}\text { Casal \& } \\
\text { Martinez }\end{array}$ & $\begin{array}{c}\text { Shepherd \& } \\
\text { Lapple }\end{array}$ \\
\hline 9.3 & 191 & 4.0 & 0.7 & 0.8 & 0.6 & 0.5 \\
\hline 11.5 & 172 & 3.6 & 0.5 & 0.7 & 0.5 & 0.4 \\
\hline 18.5 & 136 & 2.8 & 0.4 & 0.6 & 0.4 & 0.3 \\
\hline 25.4 & 116 & 2.4 & 0.3 & 0.5 & 0.4 & 0.3 \\
\hline 28.3 & 110 & 2.3 & 0.3 & 0.5 & 0.3 & 0.3 \\
\hline
\end{tabular}

\section{Cyclone pressure drop $(\Delta \mathrm{P})$}

Fig. 4 shows that the measured and the calculated pressure drops, based on $\xi_{\mathrm{c}}$ and $\mathrm{Eu}$, usually increased with the increase of inlet velocity (Karagoz \& Kaya, 2007). The comparison between the calculated pressures drops showed that the values obtained based on $\xi_{\mathrm{c}}$ equal the values obtained based on $\mathrm{Eu}$ at all vortex finder height and inlet velocity. While the calculated values based on $\xi_{\mathrm{c}}$ and $\mathrm{Eu}$, include $V_{i}$ and $V_{c}$, respectively. 
PROCESS ENGINEERING

At vortex finder height, $0.0 \mathrm{~m}$
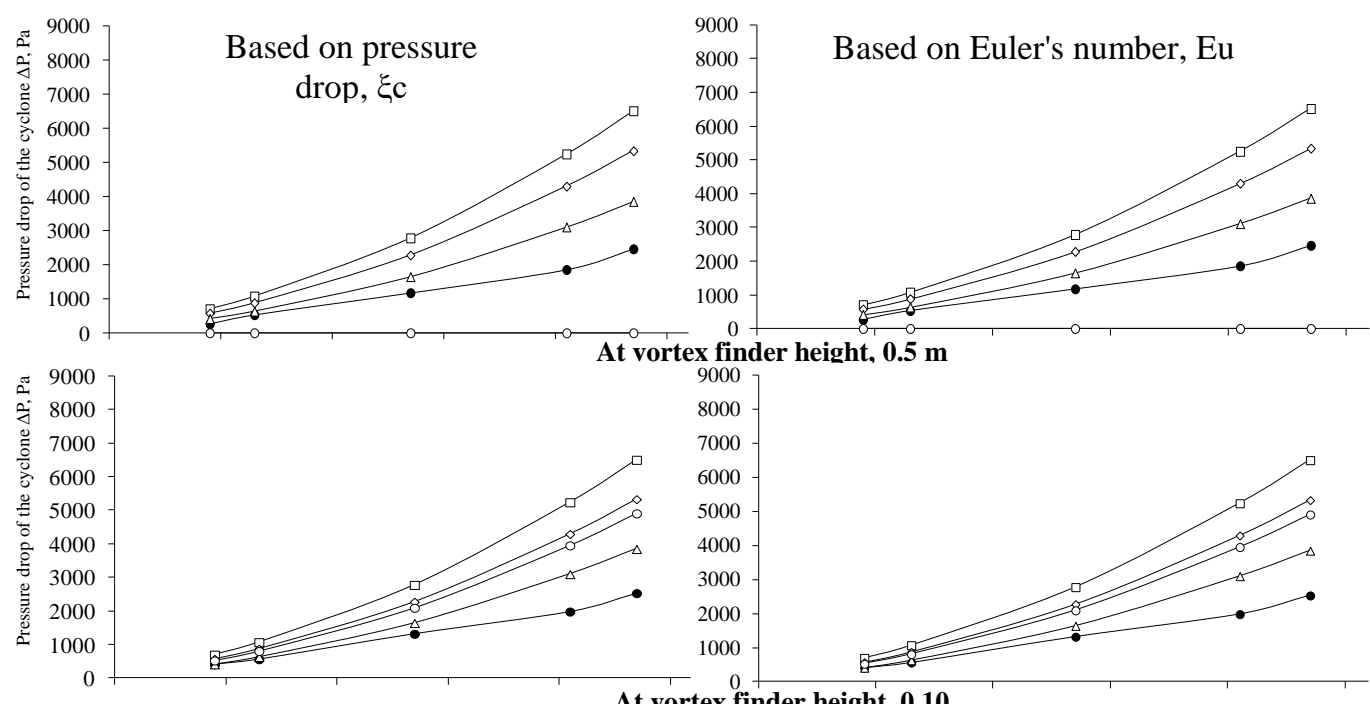

finder height, 0.5 m
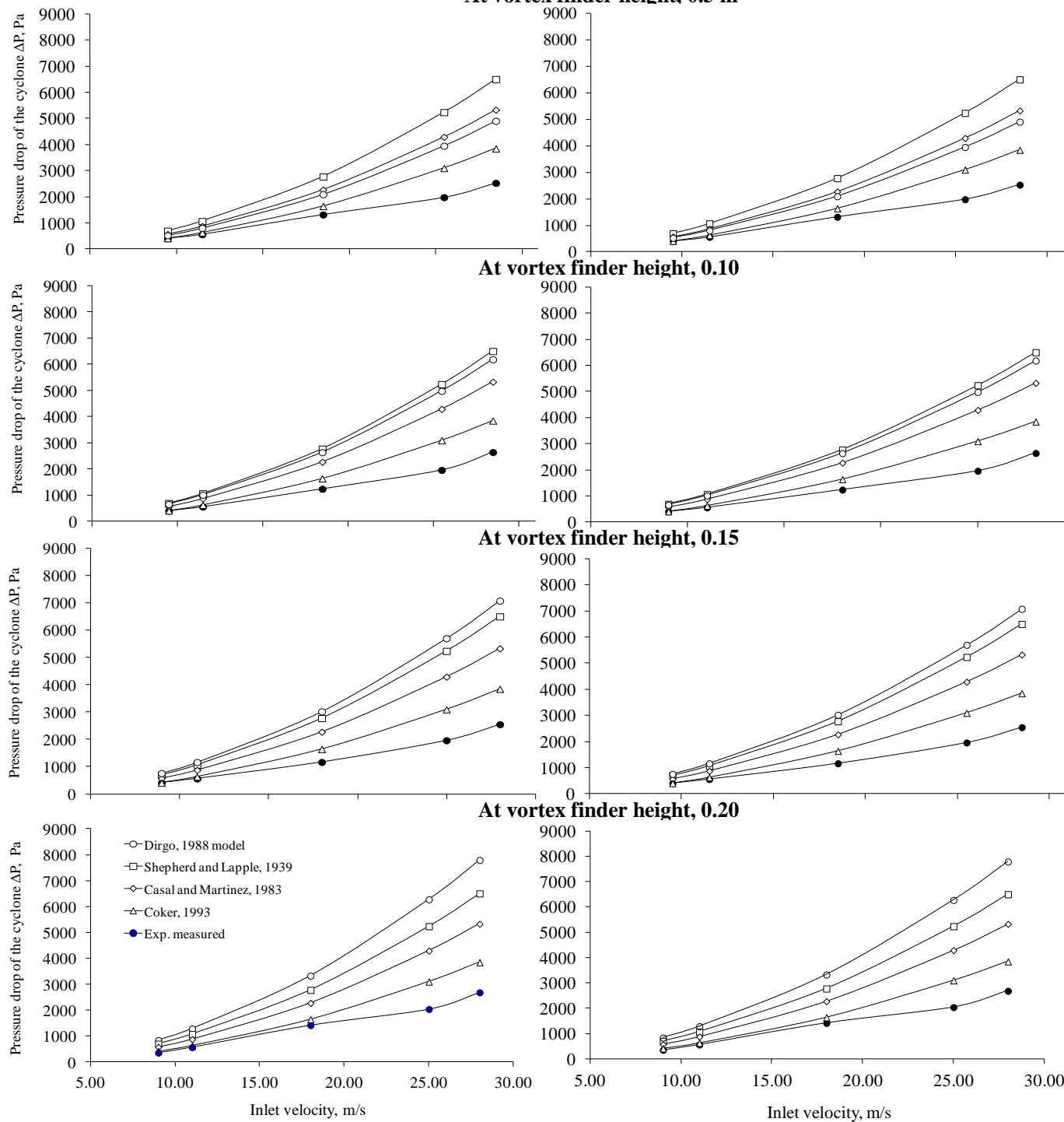

Fig. 4. The measured and the calculated pressure drops as a function of inlet velocity for different vortex finder height. 
Also showed little difference between the measured and the calculated pressure drop at 9.3 and $11.5 \mathrm{~m} / \mathrm{s}$ for all vortex finder height, while the difference increase with inlet velocity ranged from 11.5 to $28.3 \mathrm{~m} / \mathrm{s}$. A comparison between the calculated values of $\xi_{\mathrm{c}}$, at different vortex finder height in Table 7 shows doubling the vortex finder length from 0.05 to 0.10 and from 0.10 to $0.20 \mathrm{~m}$ increases the $\xi_{\mathrm{c}}$ by 25 and $26 \%$, respectively by the model Dirgo (Dewil et al., 2008) the results are in good agreement with the data published by (Elsayed \& Lacor, 2013). In addition to separation efficiency; pressure drop is considered as a major criterion to design cyclone geometry and evaluate cyclone performance. Accurate mathematical model is needed to determine the complex relationship between the pressure drop and the cyclone characteristics. The pressure drop in a cyclone separator can also be decreased or increased by varying the cyclone dimensions. For an accurate optimal design of a cyclone, it is quite necessary to use a reliable pressure drop equation for it. Therefore, the best model to predict pressure drops in this study was Cocker based on $\xi_{\mathrm{c}}$ or Eu, especially at inlet velocity from 9.3 to $18.5 \mathrm{~m} / \mathrm{s}$.

Due to using different assumptions and simplified conditions, different theoretical or semi-empirical models can lead to a significant difference between the calculated and the measured results. Predicted values by some models are twice more than experimental values, and some models are even conflicted as to which models work best (Swamee et al., 2009). Table 7: Comparison between the calculated values of $\xi \mathrm{c}$ at different vortex finder height.

\begin{tabular}{|c|c|c|c|c|}
\hline $\begin{array}{c}\text { Vortex height, } \\
\text { S (m) }\end{array}$ & $\begin{array}{c}\text { (Shepherd \& } \\
\text { Lapple, 1939) } \\
\xi_{\mathrm{c}}\end{array}$ & $\begin{array}{c}\text { (Casal \& } \\
\text { Martinez, 1983) } \\
\xi_{\mathrm{c}}\end{array}$ & $\begin{array}{c}\text { (Dirgo, } \\
1988) \\
\xi_{\mathrm{c}} \\
\end{array}$ & $\begin{array}{c}\text { (Coker, } \\
1993) \\
\xi_{\mathrm{c}} \\
\end{array}$ \\
\hline 0.00 & 12.6 & 10.3 & 0.0 & 7.4 \\
\hline 0.05 & 12.6 & 10.3 & 9.5 & 7.4 \\
\hline 0.10 & 12.6 & 10.3 & 11.95 & 7.4 \\
\hline 0.15 & 12.6 & 10.3 & 13.68 & 7.4 \\
\hline 0.20 & 12.6 & 10.3 & 15.06 & 7.4 \\
\hline
\end{tabular}

The pressure drop within a cyclone is a measure of the energy used by a cyclone and is closely related to the collection efficiency. Usually, the 
collection efficiency of a cyclone is expected to be proportional to the pressure drop (Lim et al., 2004). Fig. 5 shows the relationship between the measured pressure drops and the overall collection efficiency. The measured pressure drop increased with the increase of vortex finder height at all inlet velocity; the maximum and minimum values at the minimum inlet velocity were 264.9 and $359.5 \mathrm{~Pa}$ at 0.0 and $0.2 \mathrm{~m}$ vortex finder height, respectively. While the maximum and minimum values were 2459.7 and $2686.8 \mathrm{~Pa}$ at 0.0 and $0.2 \mathrm{~m}$ vortex finder height, respectively at maximum inlet velocity.

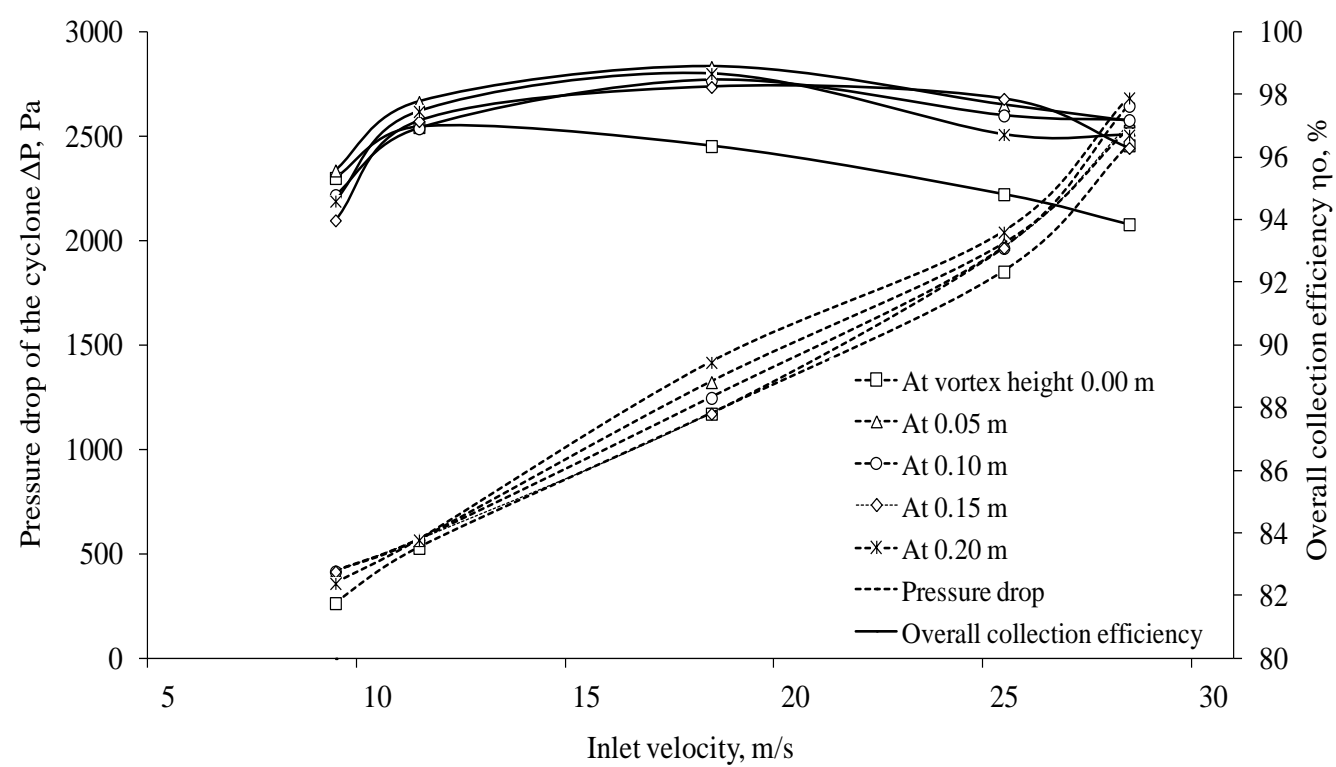

Fig. 5. Relationship between the measured pressure drops and the calculated collection efficiency at different vortex finder heights.

The overall collection efficiency increased with the increase of pressure drops at 9.3 to $18.5 \mathrm{~m} / \mathrm{s}$ inlet velocity and then slightly decreased at 18.5 to $28.3 \mathrm{~m} / \mathrm{s}$. The above mentioned results may be due to aerodynamic properties of particle and Reynold's number at height inlet velocity. On the other hand, the pressure drop influenced by the vortex finder height and inlet velocity, while the collection efficiency influenced by inlet velocity and the vortex finder height of more than zero. An accurate operating condition of cyclone pressure drop is very important because it 
relates directly to operating costs. A trade-off must be made between higher collection efficiency and low pressure drop of the cyclone. Therefore, the operation of cyclones at inlet velocity $18.5 \mathrm{~m} / \mathrm{s}$ is the better operating condition due to high collection efficiency 96.4, 98.9, 98.5, 98.3 and $98.7 \%$ and low pressure drop 1173, 1324, 1249, 1137 and $1419 \mathrm{~Pa}$ at vortex finder height $0.0,0.05,0.10,0.15$ and $0.20 \mathrm{~m}$ respectively, across the cyclone.

\section{Reynold's number}

One of the problems in calculation of cyclone efficiency is the effect of flow character in cyclones. In general, flow type is turbulent in big cyclones, and assumed friction factors and corresponding results are meaningful. However, this is not the case for small cyclones in which flow and operational conditions, such as velocity, temperature, pressure, viscosity or cyclone diameter, may be more important and their effects may differ from cyclone to cyclone, since the flow can be laminar, turbulent or transitional as mentioned by Blachman \& Lippmann (1974).

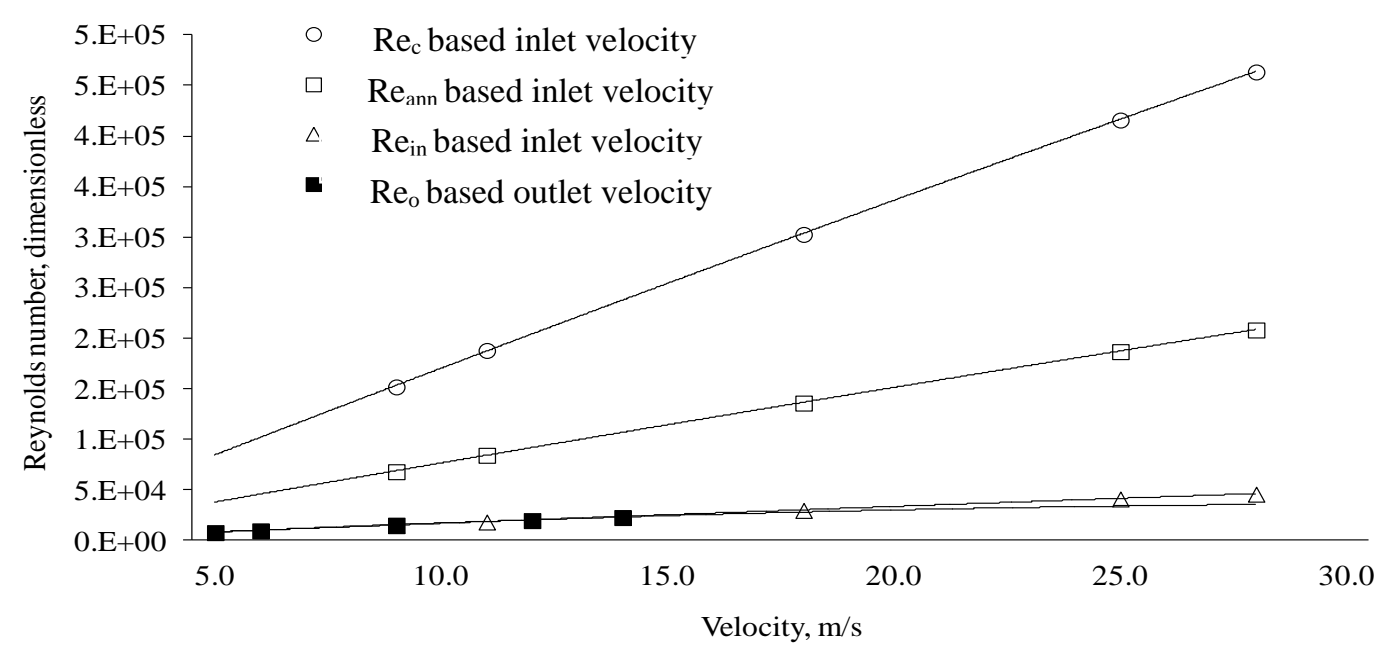

Fig. 6. Reynold's number of the cyclone at different inlet velocity.

Fig. 6 shows the Reynold's number $\mathrm{Re}_{\mathrm{c}}, \mathrm{Re}_{\mathrm{ann}}$ and $\mathrm{Re}_{\mathrm{in}}$ based on inlet velocity, and $\mathrm{Re}_{\mathrm{o}}$ based on outlet velocity. Overall, the Reynold's number more than 10,000 except $\operatorname{Re}_{o} 8362$ at outlet velocity $5.1 \mathrm{~m} / \mathrm{s}$ showed a turbulent flow regime across the cyclone. 


\section{CONCLUSIONS}

- This study included a vast number of equations to calculate the pressure drop and separation efficiency of cyclones, generally established for operation at the ambient temperatures $293 \mathrm{~K}$ and inlet velocity $9.3,11.5,18.5,25.4$ and $28.3 \mathrm{~m} / \mathrm{s}$.

- The overall collection efficiency was function to increase inlet velocity in the range from 9.3 to $18.5 \mathrm{~m} / \mathrm{s}$. The best inlet velocity was $18.5 \mathrm{~m} / \mathrm{s}$ where the overall collection efficiency were $96.4,98.9,98.5$, 98.3 and $98.7 \%$, the pressure drop were 1173, 1324, 1249, 1137 and $1419 \mathrm{~Pa}$ at vortex finder height $0.0,0.05,0.10,0.15$ and $0.20 \mathrm{~m}$ respectively.

- None of the literature correlations predicted the pressure drop with a fair accuracy within the range of experimental operating conditions; except Cocker application based on the pressure drop coefficient $\left(\xi_{\mathrm{c}}\right)$ or Euler's number $(\mathrm{Eu})$ at inlet velocity ranged from 9.3 to $18.5 \mathrm{~m} / \mathrm{s}$.

- The maximum collection efficiency of the measured and predicted value were 98.9 and $99.9 \%$, respectively at vortex finder height $0.05 \mathrm{~m}$ and $18.5 \mathrm{~m} / \mathrm{s}$ inlet velocity; while the minimum values were 92.0 and $99.9 \%$, for the measured and the predicted values, respectively at vortex finder height $0.15 \mathrm{~m}$ and $9.3 \mathrm{~m} / \mathrm{s}$ inlet velocity. The maximum difference between the measured and the predicted value of collection efficiency was $7.9 \%$ while the minimum was $1.0 \%$.

- In order to put the data into better use, the experimental data obtained in this study were compared with the existing theories. The Lapple model is easy to use and acceptable to define the collection efficiency.

\section{REFERENCES}

Alexander, R. M. (1949): Fundamentals of cyclone design and operation. Proceedings of the Australian Institute of Minerals and Metals (New Series), 152/153, 202-228.

Azadi, M., Azadi, M. and Mohebbi, A. (2010): A CFD study of the effect of cyclone size on its performance parameters. Journal of Hazardous Materials, 182, 835-841. 
Beeckmans, J. M. and kim, C. J. (1977): Analysis of the Efficiency of reverse flow cyclones, Can. J. Chem. Eng. 55, 640-643.

Blachman, M. W. and Lippmann, M. (1974): Performance characteristics of the multicyclone aerosol sampler, American Industrial Hygiene Association Journal, 35, 311-326.

Bose, P. K., Roy, K., Mukhopadhya, N. and Chakraborty, R. K. (2010): Improved theoretical modeling of a cyclone separator as a diesel soot particulate emission arrester, International Journal of Automotive Techno., Vol. 11, No. 1, pp. 1-10.

Bruce, R. M., Donald, F. Y. and Theodore, H. O. (2006): Fundamentals of Fluid Mechanics, John Wiley \& Sons, Inc., 5th edition, ISBN 0471- 7582-2.

Bryant, H. S., Silverman, R. W. and Zenz, F. A. (1983): How dust in gas affects cyclone pressure drop, Hydrocarbon Process, 62, 87-90.

Büttner, H. (1999): Dimensionless representation of particle separation characteristics of cyclones, J Aerosol Sci, 30, 1291-302.

Casal, J. and Martinez-Benet, J. M. (1983): A better way to calculate cyclone pressure drop, Chem. Eng., 90, 99-100.

Chan, W. H. (1984): Investigation of hydrodynamic behavior in cyclone separators, Ph.D. thesis, Laboratory for Power and Environmental Studies, State University, Buffalo (NY), U.S.A.

Chuah, T. G., Gimbun, J., Choong, Thomas S. Y. and Fakhru'l-Razi, A. (2003): Numerical Prediction of Cyclone Pressure Drop. Journal of Chemical Engineering and Environment, Vol. 2, No. 2, pp. 67-71.

Coker, A. K. (1993): Understand cyclone design, Chem. Eng. Progr. 28, 51-55.

Dewil, R., Baeyens, J. and Caerts, B. (2008): CFB cyclones at high temperature: Operational results and design assessment, Particuology, 6, 149-156.

Dirgo, J. (1988): Relationships between cyclone dimensions and performance, Ph.D. Thesis, Havarad University, USA. 
Elsayed, K. and Lacor, C. (2013): The effect of cyclone vortex finder dimensions on the flow pattern and performance using LES. Computers \& Fluids, Volume 71, 30 January 2013, Pages 224-239

Frank, M. W. (2003): Fluid Mechanics, McGraw-Hill, ISBN 0-07283180-4.

Gil, A., Romeo, L. M. and Corte's, C. (2001): Cold flow model of a PFBC cyclone, Powder Technology, 117, 207-220.

Hoekstra, A. J. (2000): Gas flow field and collection efficiency of cyclones, Ph.D. Thesis, Delft University of Technology, The Netherlands.

Hoffmann, A. C, Groot, M., Peng, W., Dries, H. W. A. and Kater J. (2001): Advantages and risks in increasing cyclone separator length, AIChE J., 47, 2452-60.

Hoffmann, A. C., De Jonge, R., Arends, H. and Hanrats, C. (1995): Evidence of the "natural vortex length" and its effect on the separation efficiency of gas cyclones, FiltrSeparat, 32, 799-804.

Iozia, D. L. and Leith, D. (1990): The logistic function and cyclone fractional efficiency, Aerosol Sci. Technol., 12, 598-606.

Ji, Z. L., Wu, X. L. and Shi, M. X. (1991): Experimental research on the natural turning length in the cyclone, Proceedings of Filtech Europa 91 Conference (Vol. 2, pp.583-589), Karlsruhe, Germany.

Jiao, J., Zheng, Y., Sun, G. and Wang, J. (2006): Study of the separation efficiency and the flow field of a dynamic cyclone, Sep. Purif. Technol., 49, 157-166.

Karagoz, I. and Kaya, F. (2007): CFD investigation of the flow and heat transfer characteristics in a tangential inlet cyclone, International Communications in Heat and Mass Transfer 34, 1119-1126.

Kuo, K. Y. and Tsai, C. J. (2001): On the theory of particle cutoff diameter and collection efficiency of cyclones, Aerosol and air Quality Research, (2001) Vol. 1, No. 1, pp. 47-56.

Lapple, C. E. (1950): Gravity and centrifugal separation, Industrial Hygiene Quarterly, 11, 40-47. 
Lees, F. P. (2005): Loss Prevention in the Process Industries (Partially updated by S. Mannan), vols. 1-3, Elsevier/ButterworthHeinemann, Oxford, UK.

Lim, K. S., Kim, H. S. and Lee, K. W. (2004): Comparative performances of conventional cyclones and a double cyclone with and without an electric field, Aerosol Science, 35, 103-116.

Moore, M. E. and McFarland, A. R. (1993): Performance modelling of single-inlet aerosol sampling cyclones, Environ. Sci. Technol., 27, 1842-1848.

Overcamp, T. J. and Scarlett, S. E. (1993): Effect of Reynolds number on the Stokes number of cyclones, Aerosol Sci. Technol., 19, 362370.

Pant, K., Crowe, C. T. and Irving, P. (2002): On the design of miniature cyclones for the collection of bioaerosols, Powder Technology, $125,260-265$.

Qian, F., Zhang, J. and Zhang, M. (2006): Effects of the prolonged vertical tube on the separation performance of a cyclone, J. Hazard. Mater, 136, 822-829.

Ramachandran, G., Leith, D., Dirgo, J. and Feldman, H. (1991): Cyclone optimization based on a new empirical model for pressure drop, Aerosol Science and Technology, 15, 135-148.

Safikhani, H., Akhavan-Behabadi, M., Shams, M. and Rahimyan, M. H. (2010): Numerical simulation of flow field in three types of standard cyclone separators, Advanced Powder Technol., 21, 435442.

Saltzman, B. E. and Hochstrasser, J. M. (1983): Design and performance of miniature cyclones for respirable aerosol sampling, Environ. Sci. Techno., 17, 418-424.

Shepherd, C. B. and Lapple, C. E. (1939): Air Pollution Control: A Design Approach, In Cyclones" 2nd Edition, C. David Cooper, and F. C. Alley, pp 127-139, Illinois: Woveland Press Inc. 
Stairmand, C. J. (1951): The design and performance of cyclones, Transactions of the Institution of Chemical Engineering 29, 357383.

Svarovsky, L. (1981): Solid-gas separation. Handbook of Powder Technology, vol. 3, Chap. 1-3, Elsevier Scientific Publishing Company.

Svarovsky, L. (1986): Solid-gas separation, In D. Geldart (Ed.), Gas fluidization technology, New York, John Wiley and Sons Ltd (Chapter 8):

Swamee, P. K., Aggarwal, N. and Bhobhiya, K. (2009): Optimum design of the cyclone separator, American Institute of Chemical Engineers (A.I.Ch.E.) 55, 2279-2283.

Wang, L. (2004): Theoretical Study of Cyclone Design, Ph.D. Thesis, Texas A\&M University, College Station, USA.

Yalcin, T., Kaukolin, E. and Byers, A. (2003): Axial inlet cyclone for mineral processing applications, Minerals Engineering, 1613751381.

Zhu, Y. and Lee K. W. (1999): Experimental study on small cyclones operating at high-flow rates, J. Aerosol Sci., 30, 1303-1315.

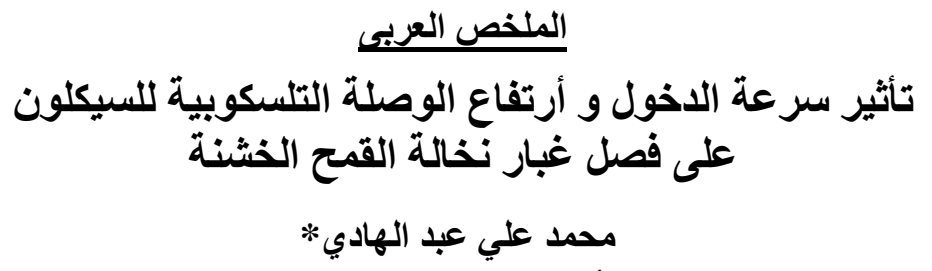

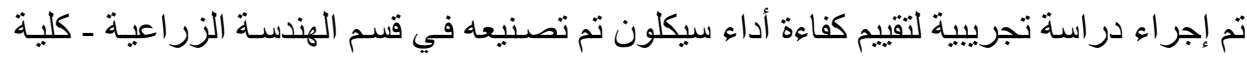

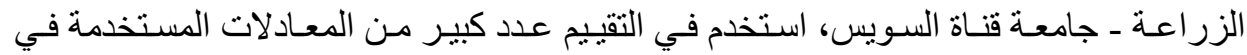

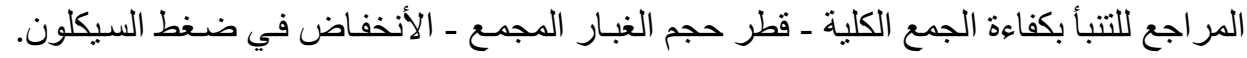

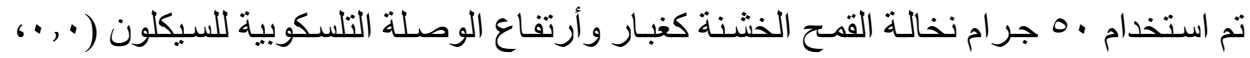

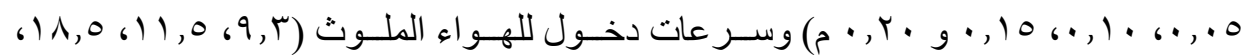

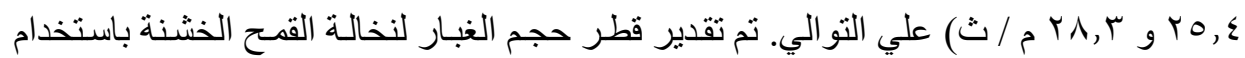

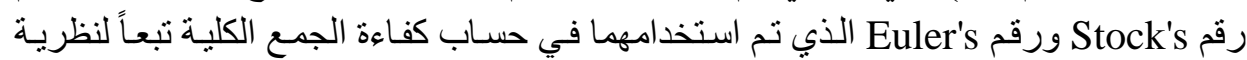

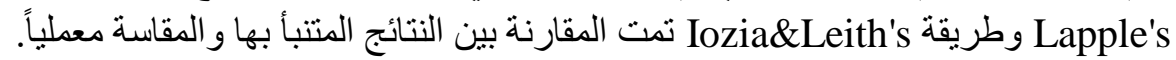
* استاذ مساعد ـ قسم الهندسة الزراعية ـ كلية الزراعةـ جامعة قناة السويس. 


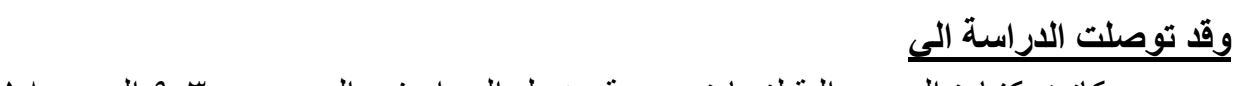

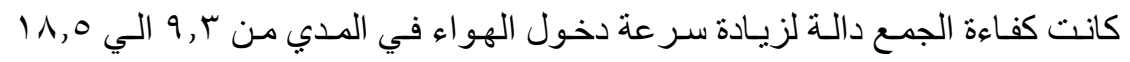

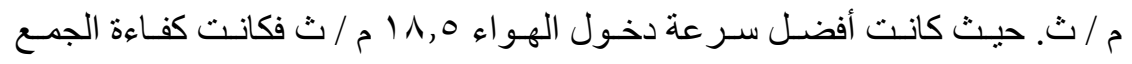

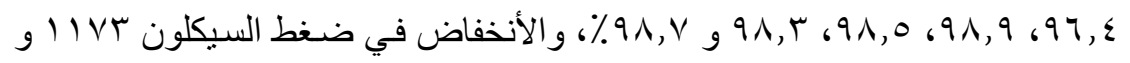

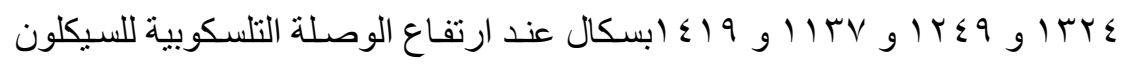

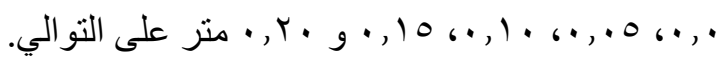
لا يوجد أي من المعادلات في المر اجع للتنبأ للأنخفـاض في ضنغط السيكلون مـع دقة

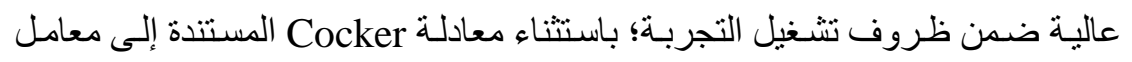

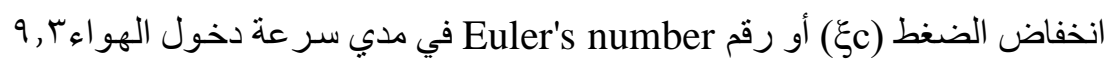

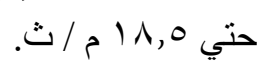

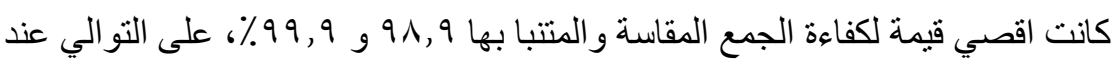

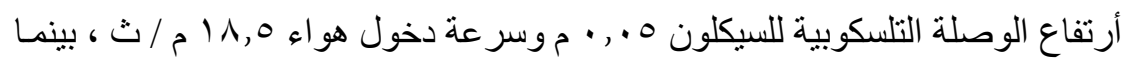

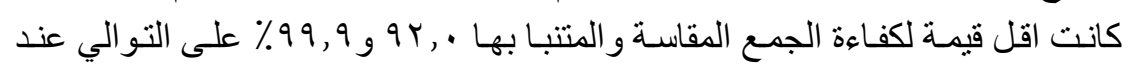

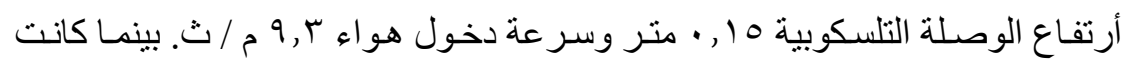

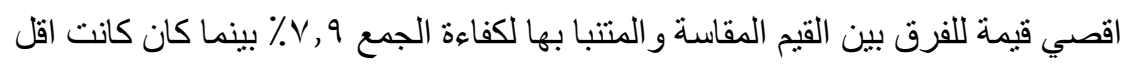

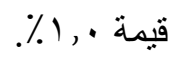

تم مقارنة القيم المقاسة مع القيم المتنبأ بها من المعـادلات المستخدمة في الدراسـة وجد ان نموذج Lapple كان سهل الاستخدام ومقبول لتحديد كفاءة الجمع. 